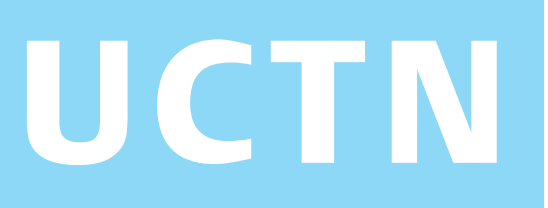

\title{
Endoscopic band ligation: a novel therapy for bleeding gastric antral vascular ectasia
}

We report the first case of bleeding gastric antral vascular ectasia (GAVE) treated successfully by endoscopic band ligation after failure of argon plasma coagulation (APC) to achieve hemostasis.

A 55-year-old woman presented with a 1month history of recurrent melena and severe anemia (hemoglobin $4.5 \mathrm{~g} / \mathrm{dL}$ ) caused by severe bleeding from GAVE of idiopathic origin. She was transfused with 4 units of packed red blood cells. She underwent two sessions of APC in an attempt to achieve hemostasis but responded suboptimally, and the melena recurred within 2 weeks with a drop in the hemoglobin from a post-transfusion level of $11.0 \mathrm{~g} / \mathrm{dL}$ to $7.9 \mathrm{~g} / \mathrm{dL}$ (Figure $\mathbf{1}$ ). Endoscopic band ligation was considered as a salvage therapy for the APC-refractory GAVE lesion and two sessions were performed with a 2-week interval between them by applying five and eleven rubber bands respectively in the antrum (Figure 2). After the endoscopic band ligation, there was clinical and endoscopic improvement and a rise in the hemoglobin to $10.4 \mathrm{~g} / \mathrm{dL}$ (Figure 3 ). The adverse effects after banding were epigastric pain requiring oral analgesia and ulcers at the sites of band application, which healed completely (Figure 4). In the 15 months of followup after the band ligation no gastrointestinal bleeding occurred and her hemoglobin remained stable, with persisting improvement of the endoscopic lesions (Figure 5).

GAVE is an important cause of overt or occult gastrointestinal bleeding, and mainly affects elderly women [1]. Occult blood loss is the most common feature, and transfusion dependence is seen in a half to two-thirds of cases. Because of a lack of randomized trials, the best treatment modality remains unknown, but APC is currently the most common and popular method of treatment $[2,3]$.

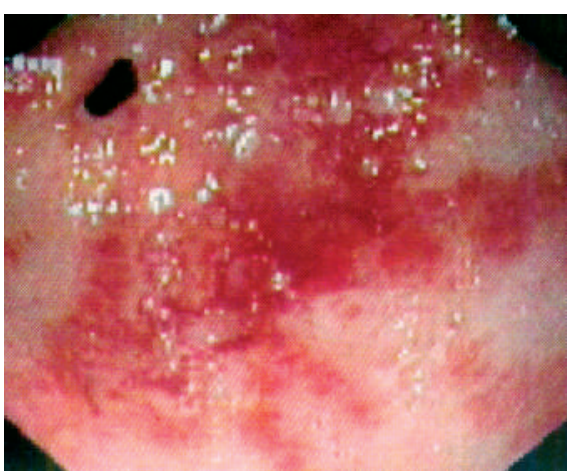

Figure 1 Heavily bleeding lesions of gastric antral vascular ectasia (GAVE) after two sessions of argon plasma coagulation.

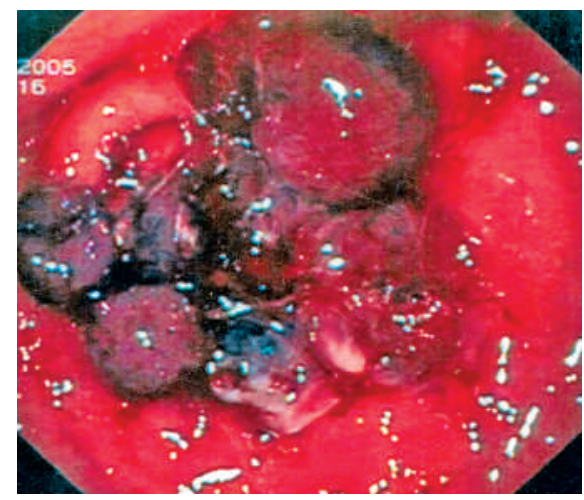

Figure 2 The bands applied at the endoscopic band-ligation procedure, seen here to be occupying the entire antrum (up to the incisura angularis) that was affected by GAVE.

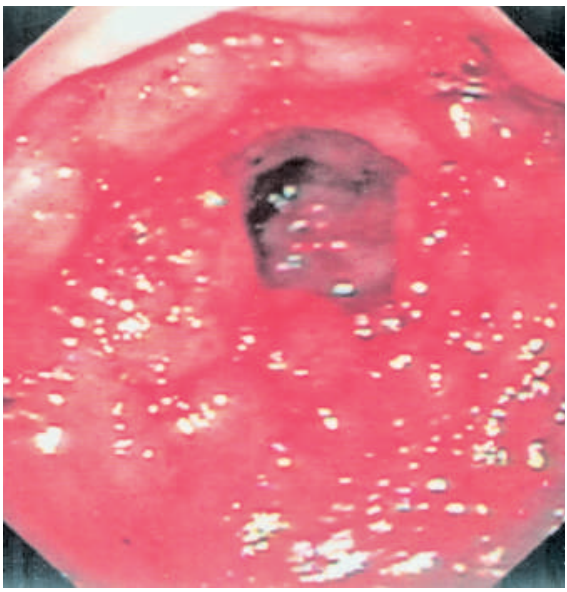

Figure 3 Endoscopic view showing almost complete disappearance of the severe GAVE lesions after the second session of endoscopic band ligation.

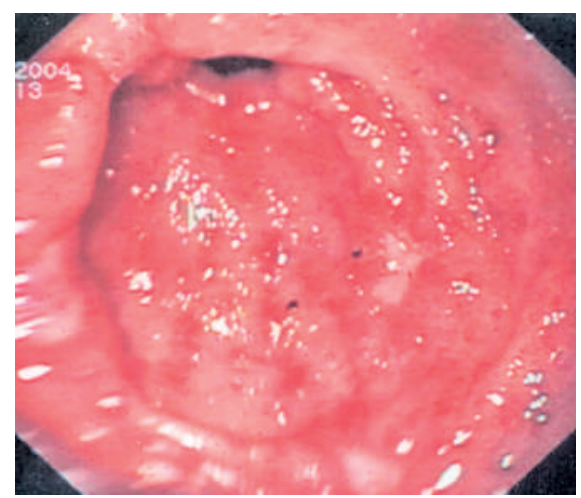

Figure 4 Ulcers (with white bases) in the antrum at the site of previous band applications.

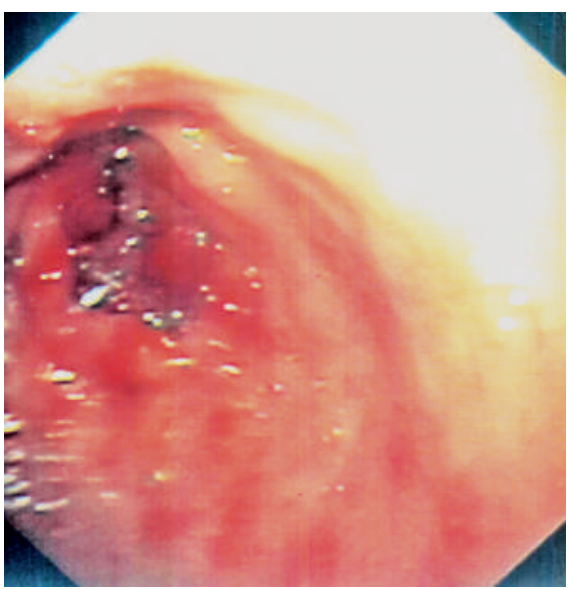

Figure 5 Eradication of the GAVE lesions was confirmed at follow-up 8 months after the endoscopic band ligation.

We used endoscopic band ligation to treat GAVE in this patient because of its proved safety, effectiveness, and simplicity in achieving hemostasis in variceal and various nonvariceal gastrointestinal bleeding conditions [4,5]. Unlike APC, endoscopic band ligation can be applied all over the antrum in a single session without causing the discomfort associated with excessive gaseous distension, and because it is a very simple and cost-effective method that does not require any costly equipment, accessories, or advanced training. Its simplicity, safety, and cost-effectiveness make it a superior alternative to APC 
for the treatment of bleeding GAVE, especially in countries with limited resources. In conclusion, endoscopic band ligation is a novel therapy for GAVE and can also be used as a salvage therapy if other treatment modalities fail.

\section{Endoscopy_UCTN_Code_TTT_1AO_2AZ}

\section{R. Kumar, S. Mohindra, H. S. Pruthi}

Department of Medical Gastroenterology, Bhopal Memorial Hospital and Research Centre, Bhopal, India.
${ }^{1}$ Burak KW, Lee SS, Beck PL. Portal hypertensive gastropathy and gastric antral vascular ectasia (GAVE) syndrome. Gut 2001; 49: 866-872

2 Sebastian S, O'Morain CA, Buckley MJ. Review article: current therapeutic options for gastric antral vascular ectasia. Aliment Pharmacol Ther 2003; 18: 157- 165

${ }^{3}$ Kwan V, Bourke MJ, Williams SJ et al. Argon plasma coagulation in the management of symptomatic gastrointestinal vascular lesions: experience in 100 consecutive patients with long-term follow-up. Am J Gastroenterol 2006; 101: 58-63

${ }^{4}$ Matsui S, Kamisako T, Kudo M et al. Endoscopic band ligation for control of nonvariceal upper GI hemorrhage: comparison with bipolar electrocoagulation. Gastrointest Endosc 2002; 55: 214-218

${ }^{5}$ Ertekin C, Taviloglu K, Barbaros U et al. Endoscopic band ligation: alternative treatment method in nonvariceal upper gastrointestinal hemorrhage. J Laparoendosc Adv Surg Tech A 2002; 12: 41 - 45
Corresponding author

R. Kumar, MD, DM

Department of Medical Gastroenterology Bhopal Memorial Hospital and Research Centre

Raisen Bypass Road

Bhopal 462038

India

Fax: +91-755-2748309

Email: drrakeshk@gmail.com 